\title{
Effect of process parameters on surface roughness of hybrid investment casting
}

\author{
Parlad Kumar $^{1} \cdot$ Inderpreet S. Ahuja $^{1} \cdot$ Rupinder Singh $^{2}$
}

Received: 23 October 2015/Accepted: 17 February 2016/Published online: 3 March 2016

(C) Springer International Publishing Switzerland 2016

\begin{abstract}
Fused deposition modelling (FDM) is one of the additive manufacturing technologies that can be effectively used for making patterns for investment casting. This method is considered to be economical for low volume of production as tooling is not involved in this process. However, the surface finish of the patterns produced by using FDM machine is poor as compared to wax patterns produced by using a die. The surface finish of the castings produced by the investment casting process are dependent on the surface finish of the pattern, therefore in order to use plastic patterns instead of wax patterns, there is a need to improve the surface finish of the FDM patterns. For this purpose, a coating of thin layer of wax has been proposed on the plastic patterns made by using FDM. In this paper the effect of wax coating and other process parameters has been studied on the surface roughness of the castings.
\end{abstract}

Keywords Fused deposition modelling - Investment casting $\cdot$ Additive manufacturing $\cdot$ Surface roughness

Rupinder Singh

rupindersingh78@yahoo.com

Parlad Kumar

pkgarg4050@gmail.com

Inderpreet S. Ahuja

ahujaips@yahoo.co.in

1 Department of Mechanical Engineering, Punjabi University, Patiala, Punjab, India

2 Department of Production Engineering, Guru Nanak Dev Engineering College, Ludhiana, Punjab, India

\section{Introduction}

Additive manufacturing (AM) technologies were emerged in 1987 with the introduction of 'Stereolithography' technology. In subsequent years, various other AM technologies such as: fused deposition modelling (FDM), selective laser sintering and laminated object manufacturing, solid ground curing, poly jet etc. were introduced. The major benefit of AM technologies is their capability to convert a three dimensional CAD model into a physical model directly without using any tool or die.

The AM system based on FDM technology was introduced in April 1992 by Stratasys [1]. In FDM technology, thin plastic layers are added to make three-dimensional models. These models can be used for many applications. One important application is the use of these models as investment casting patterns instead of the conventional wax patterns [2-4]. The use of FDM-based patterns can eliminate the requirement of costly and timeconsuming hard tooling required for making wax patterns. The hard tooling is considered to be economical only when a large number of similar pieces are required and proves to be uneconomical when only one or few pieces are required, such as for making customised parts, patientspecific implants, during design iterations, prototype development and functional testing. Moreover, to accommodate any modification in the design, every time a new die is required, which again increase the cost and lead time. On the other hand, by using FDM-based patterns, any change in design can be easily accommodated by just modifying the drawing. This method makes the investment casting viable for low- and very low-volume projects [5-8]. The casting prototypes can be used for design and metallurgical evaluation prior to mass production [9]. The use of modern FDM technology in 
conventional investment casting process can be termed as hybrid investment casting [10].

However, the major problems in using the FDM-based plastic patterns are: shell cracking, ash accumulation in the cavity and poor surface finish of the product. The problem of shell cracking is due to the thermal expansion of the plastic patterns and can be reduced by making the patterns hollow using QuickCast build styles. The concept of QuickCast is based on the fact that hollow structures would soften at lower temperatures and collapse inwards upon itself before critical stress levels are developed [2]. However, this method cannot eliminate the problem completely, especially in the large parts. The second problem is the ash, which is produced in the mould due to burning of the plastic pattern. This ash can be removed by cleaning the mould with water or compressed air before pouring the molten metal [8]. The poor surface finish of the casting is due to poor surface finish of the patterns, as the mould duplicates the kind of surface finish presented by the pattern. To achieve good surface finish, many researchers have conducted numerous studies to make FDM parts suitable for investment casting purpose.

Anitha et al. [11] and Ahn et al. [12] found that the poor surface finish of the FDM parts is due to the resolution of the FDM process, which is dictated by the filament thickness. Garg [13] concluded that there are a large number of conflicting factors which influence the surface finish and dimensional accuracy of FDM independently or in interaction with others. Vasudevarao et al. [14] found that layer thickness and part orientation have significant effect on the roughness of parts fabricated using the FDM machine. Thrimurthulu et al. [15] suggested an approach to minimise the surface roughness by optimising the orientation of the built part in the FDM machine. Bakar et al. [16] recommended that besides applying a thin layer, appropriate values of contour width and internal raster should be used for making parts with a good surface finish. Chang and Huang [17] examined the effects of extruding parameters including contour width, contour depth, part raster width and raster angle to improve the FDM process. Galantucci et al. [18] suggested that the surface finish of FDM parts can be improved by chemical treatment also without any major effect on the mechanical properties. Kuo et al. [19] used aluminium-filled epoxy resin as a filler to improve the surface quality of wax injection tool fabricated by FDM. Boschetto and Bottini [20] found that the barrel finishing method can be used for reducing the surface roughness of the FDM parts.

In this paper, it has been suggested that a thin layer of wax on the FDM parts can provide good surface finish to the castings produced by using these parts as sacrificial patterns in the investment casting process. Moreover, it has been found that the wax coating can also reduce the chances of shell cracking. In addition to this, the effect of other casting process parameters on the surface roughness has also been studied. Experiments have been conducted to

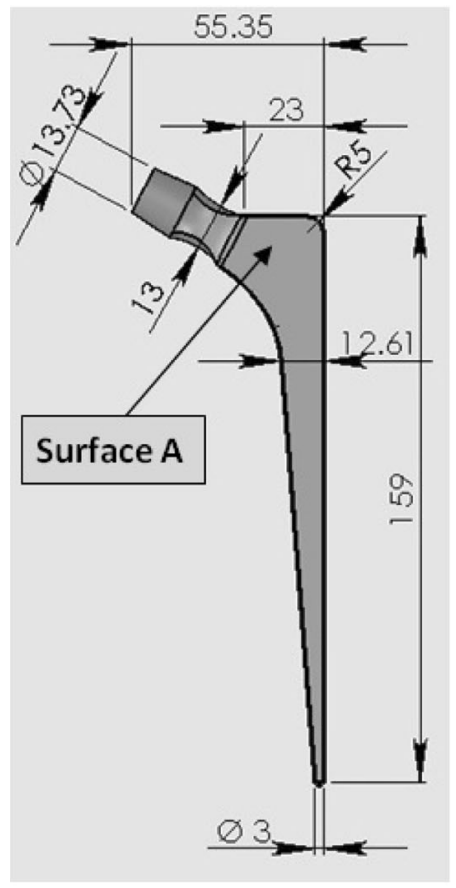

(a) Benchmark 1

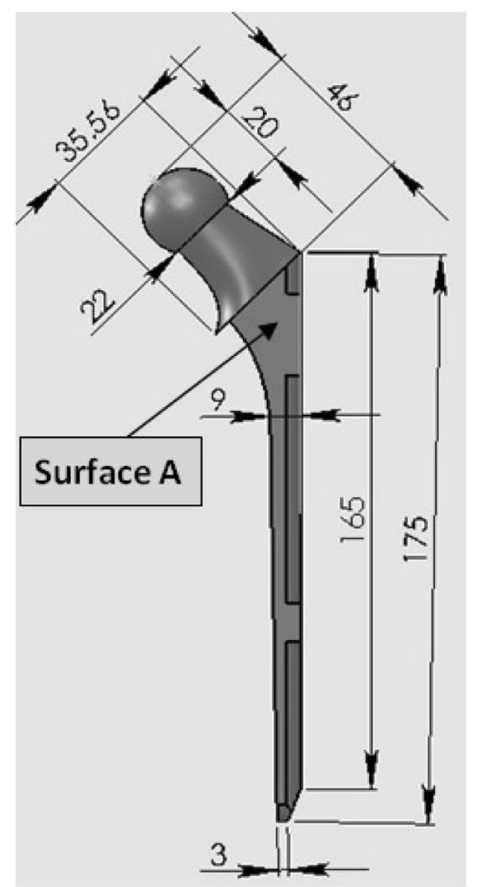

(b) Benchmark 2

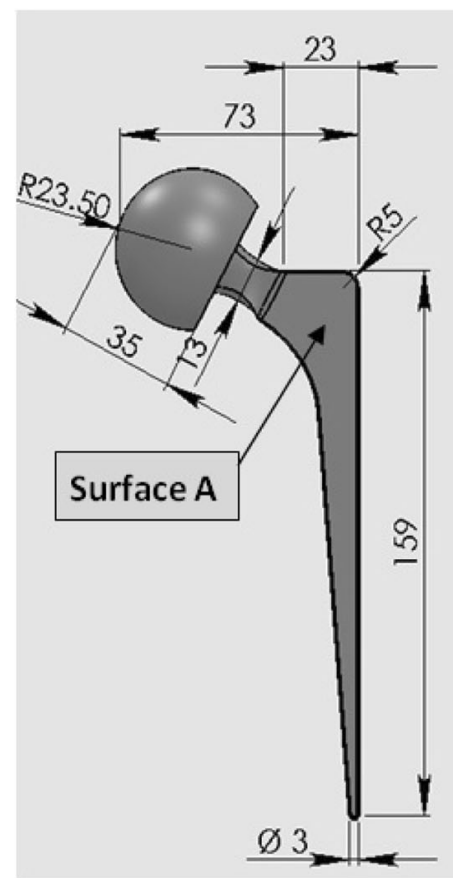

(c) Benchmark 3

Fig. 1 Three-dimensional views of benchmarks (all dimensions are in $\mathrm{mm}$ ) 
find the optimum values of the parameters to achieve the best possible surface finish. For the purpose of surface roughness comparison, a common surface marked as ' $\mathrm{A}$ ' (see Fig. 1) was selected on all cast components.

\section{Methodology}

\subsection{Identification of process parameters}

The aim of the study is to find a set of input parameters to minimise the surface roughness of the castings produced by using FDM patterns in the investment casting process. For this purpose, the various input parameters that may influence the surface roughness were identified on the basis of a preliminary study.

\subsubsection{Preliminary study}

At the start of the study, two types of master patterns were prepared. In the first type, ABS plastic pattern was coated with a thin layer of wax and in second type no coating was used on ABS plastic pattern. It was observed that there is decrease in surface roughness of the castings due to wax coating of patterns.

The cooling rate and solidification time of the casting depend on the V/A ratio of the casting and mould thickness. The VIA ratio pertains to the ratio of volume of the casting to the heat-emitting surface of the casting. As the V/A ratio increases, the solidification time of the casting also increases [21, 22]. The increased solidification time is responsible for coarse grain sizes, whereas at high cooling rate fine grain sizes are produced. During pilot experiments, it was observed that the fine grain structure produced better surface finish as compared to the coarse grain structure. To explore the effect of V/A ratio and mould thickness, three different types of benchmarks (biomedical implants having different $V / A$ ratios) were selected and their actual sizes produced. The calculated values of $V / A$ ratios for these benchmarks are 2.75, 3.34 and 4.25, respectively.
The orientation of the pattern during its manufacturing in the FDM machine also affects the surface roughness [14, 15]. To study the effect of part orientation, three different orientations of $0^{\circ}, 45^{\circ}$ and $90^{\circ}$ were selected.

The FDM machine can produce three different types of model interiors, i.e. low density, high density and solid. The solid patterns are rigid and strong, whereas the lowdensity patterns are cost-effective and produce less quantity of ash in the cavity after burning them to make the mould. All these three types of pattern's interior have been studied.

In investment casting process, the mould is prepared by coating a number of slurry layers on the casting tree. An increase in the number of slurry layers would increase the thickness of the mould. There is no direct method to control the thickness of the mould except controlling the number of slurry layers. The mould thickness affects the rate of cooling of the casting and any increase in mould thickness decreases the rate of heat dissipation and, consequently, the time of solidification increases. During preliminary experiments, different numbers of layers were tried and it was observed that there were chances of mould cracking if the layers were reduced to 6; on the other hand, if the layers were increased to 10 , there were issues regarding loss of permeability, cost and time. Therefore, to find the effect of the rate of cooling seven, eight and nine slurry layers have been selected as three levels for this factor.

To find the effect of the rate of cooling, seven, eight and nine slurry layers were selected as three levels for this factor. It has been observed during the preliminary experiments that there are chances of mould cracking if the layers are reduced to 6 , and, on the other hand, if the layers are increased to 10 there are issues regarding loss of permeability, cost and time. Further, to study any possible effect of different grades of material, three different grades of metal were selected. Three grades of austenite stainless steel (304L, 316 and 304) were selected due to their biocompatible nature.

The list of various input factors along with their levels is given in Table 1.
Table 1 Different input factors and their levels

\begin{tabular}{llllll}
\hline S. no. & Input factor & Designation & Levels & \\
\cline { 4 - 5 } & & & Level 1 & Level 2 & Level 3 \\
\hline 1 & Type of pattern & TP & Wax-coated ABS & Uncoated ABS & - \\
2 & Volume to area ratio & VA & 2.75 & 3.34 & 4.25 \\
3 & Orientation of the pattern & OP & $0^{\circ}$ & $45^{\circ}$ & $90^{\circ}$ \\
4 & Density of the pattern & DP & Low & High & Solid \\
5 & Mould thickness (no. of layers) & MT & 7 & 8 & 9 \\
6 & Grade of material & GM & 304L & 316 & 304 \\
\hline
\end{tabular}




\subsection{Selection of benchmarks}

Three different benchmarks having practical importance and different V/A ratios were selected. These parts are the different types of prosthetic biomedical implants that are used in total hip replacement of the joint of the human body. These biomedical implants are generally manufactured by the investment casting process. The $3 \mathrm{D}$ views and important dimensions of these benchmarks are shown in Fig. 1a-c.

\subsection{Design of experiments}

The Taguchi's orthogonal array was used for the design of the experiments. In this study, the sum of the number of degrees of freedom for the selected six parameters is 11 , and there is one factor with two levels and five factors with three levels. Therefore, the appropriate orthogonal array for this case is $\mathrm{L}_{18}\left(2^{1} \times 3^{7}\right)$. The $\mathrm{L}_{18}$ orthogonal array along with independent variables and their selected levels used for the experiments is shown in Table 2 .

\subsection{Preparation of FDM patterns}

For producing the FDM patterns, three-dimensional solid models of the parts (Fig. 1) were prepared using Solidworks Office Premium 2010 software and exported as STL

Table 2 L18 experimental design for selected input factors and their levels

\begin{tabular}{|c|c|c|c|c|c|c|}
\hline \multirow[t]{2}{*}{ Exp. no. } & \multicolumn{6}{|l|}{ Input factor } \\
\hline & TP & VA & OP & DP & MT & GM \\
\hline 1 & Wax coated & 2.75 & 0 & Low & 7 & $304 \mathrm{~L}$ \\
\hline 2 & Wax coated & 2.75 & 45 & High & 8 & 316 \\
\hline 3 & Wax coated & 2.75 & 90 & Solid & 9 & 304 \\
\hline 4 & Wax coated & 3.34 & 0 & Low & 8 & 316 \\
\hline 5 & Wax coated & 3.34 & 45 & High & 9 & 304 \\
\hline 6 & Wax coated & 3.34 & 90 & Solid & 7 & $304 \mathrm{~L}$ \\
\hline 7 & Wax coated & 4.25 & 0 & High & 7 & 304 \\
\hline 8 & Wax coated & 4.25 & 45 & Solid & 8 & $304 \mathrm{~L}$ \\
\hline 9 & Wax coated & 4.25 & 90 & Low & 9 & 316 \\
\hline 10 & Uncoated & 2.75 & 0 & Solid & 9 & 316 \\
\hline 11 & Uncoated & 2.75 & 45 & Low & 7 & 304 \\
\hline 12 & Uncoated & 2.75 & 90 & High & 8 & $304 \mathrm{~L}$ \\
\hline 13 & Uncoated & 3.34 & 0 & High & 9 & $304 \mathrm{~L}$ \\
\hline 14 & Uncoated & 3.34 & 45 & Solid & 7 & 316 \\
\hline 15 & Uncoated & 3.34 & 90 & Low & 8 & 304 \\
\hline 16 & Uncoated & 4.25 & 0 & Solid & 8 & 304 \\
\hline 17 & Uncoated & 4.25 & 45 & Low & 9 & $304 \mathrm{~L}$ \\
\hline 18 & Uncoated & 4.25 & 90 & High & 7 & 316 \\
\hline
\end{tabular}

file to the FDM machine software. The FDM machine used for this purpose was Stratasys uPrint SE 3D printer. The layer thickness in the FDM machine was kept at $0.254 \mathrm{~mm}$ for all the pieces. According to trial runs of Table 2, 18 patterns were prepared using ABS plastic material supplied by Stratasys. Nine sprues were also prepared using the FDM machine, and a liquid adhesive was used to attach two patterns on each sprue as shown in Fig. 2. Out of the 18 patterns, 9 were preheated with hot air and then coated with a thin layer of wax by just dipping and removing from a pool of molten wax maintained at $100{ }^{\circ} \mathrm{C}$ as shown in Fig. 3.

\subsection{Investment casting}

All the 18 patterns were coated with different number of slurry layers according to the trial runs of the $\mathrm{L}_{18}$ array. The patterns were burnt out in a furnace at $1080{ }^{\circ} \mathrm{C}$ to get moulds for pouring the molten metal. During the burnout process, cracks were observed in the moulds for experiment trial number 14

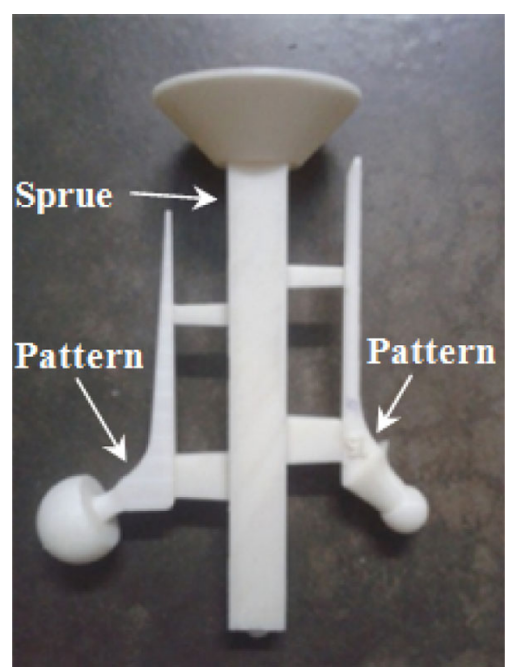

Fig. 2 FDM Patterns attached with sprue

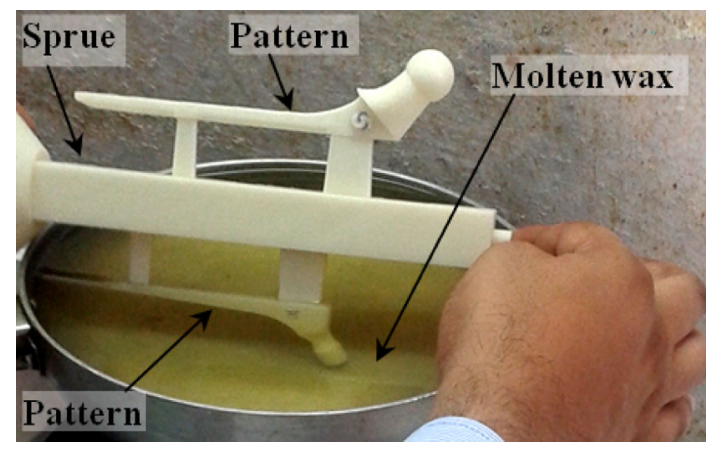

Fig. 3 Wax coating on the ABS pattern 
and 18. In these experimental runs, the moulds were prepared using uncoated high-density patterns and with seven layers of slurry. The cracking was due to the force of thermal expansion of plastic patterns on thin moulds prepared by seven layers. However, the moulds prepared by using uncoated patterns having eight or nine slurry layers were able to withstand the thermal expansion force exerted by the pattern. It should be noted that for experiment 11 , the mould prepared by using uncoated low-density patterns and with seven layers of slurry is not cracked, due to less expansion of the low-density pattern. On the other hand, all the moulds prepared by using patterns with wax coating on their surface survived during the burning out process, due to the fact that wax has a low melting point and burns well before the pattern, leaving some space for expansion of the pattern.

The cracked moulds were removed from the furnace and, after minor repair with the slurry, again heated up in the furnace. All the moulds were cleaned using pressurised air and different grades of metal were poured in the moulds to get 18 pieces of castings as shown in Fig. 4. Three repetitions of all the experiments were conducted to check the repeatability of the experiments and minimise the error. In this way, in three different sets, a total of 54 pieces of castings were produced.

\section{Results and discussion}

The surface roughness $\left(R_{\mathrm{a}}\right)$ was measured on all the castings for flat surface 'A' as shown in Fig. 1. Mitotoyo Surf Test SJ201 was used to measure the surface roughness as

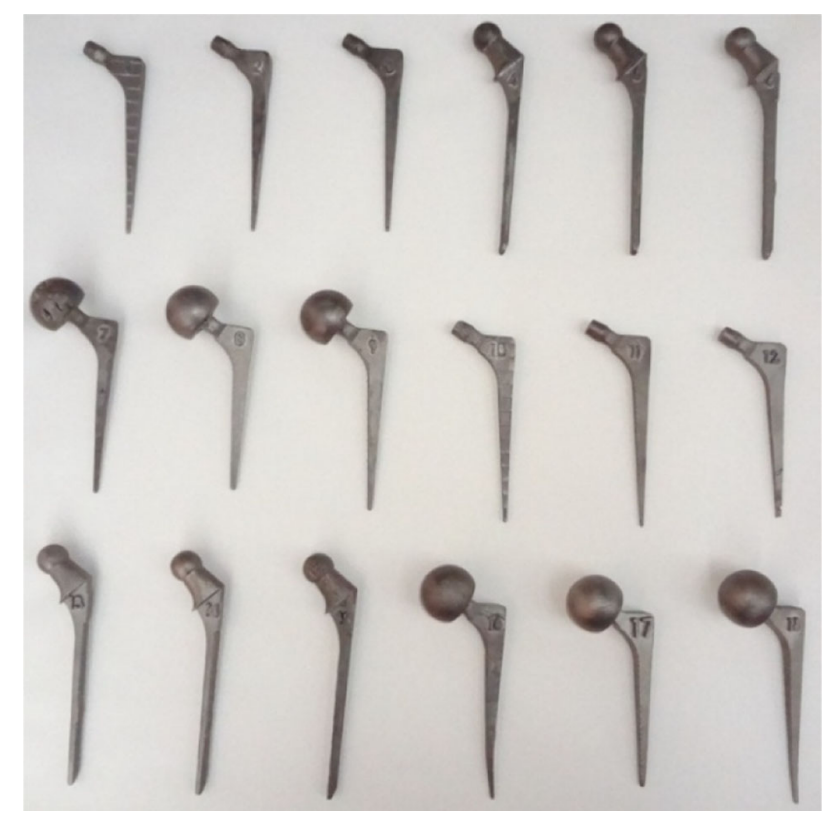

Fig. 4 One set of the specimens after casting per ISO 1997 standard. The signal to noise $(S / N)$ ratio was calculated for each surface roughness value. The $S / N$ ratio is used to determine the influence and variation caused by each factor. The advantage of using the $S / N$ ratio is that it uses a single measure, mean-square deviation (MSD), which incorporates the effect of changes in mean as well as the variation (standard deviation) with equal priority [23]. In this design situation where the surface roughness is to be minimised, the $S / N$ ratio for surface roughness was calculated on the basis of 'lower is better' approach which is a logarithmic function based on mean-square deviation (MSD) and is given by:

$S / N_{\mathrm{LB}}=-10 \log (\mathrm{MSD})=-10 \log \left[\frac{1}{r} \sum_{i=0}^{r} Y_{i}^{2}\right]$,

where MSD is the mean-square deviation, $Y_{i}$ the observed value of the response characteristic and $r$ the number of repetitions.

The observed surface roughness values for the three trial runs and their calculated $S / N$ ratios are shown in Table 3. The analysis was made using the MINITAB 16 statistical software package [24].

Table 3 represents the values of all the factors for the different experiments. The experiments were repeated three times and the obtained values for surface roughness were designated as R1, R2 and R3. The $S / N$ ratio was calculated from these values by using Eq. (1).

\subsection{Analysis of the $S / N$ ratio}

The mean $S / N$ ratios for all the factors and all the levels were calculated and are shown in Table 4 . The factors are ranked according to their effect on surface roughness with higher ranks given to the factors having higher delta value. The higher the rank, the higher is the significance. The delta value is calculated by finding the difference between the maximum and minimum values of the mean $S / N$ ratios for each factor. The mean is calculated using Eq. (2):

$A=\frac{X_{1}+X_{2}+X_{3}+\ldots+X_{i} \ldots+X_{n}}{n}$,

where $X_{i}$ is the $S / N$ ratio of the $i$ th experimental run, $A$ the mean of the $S / N$ ratios and $n$ the number of experiments.

Perusal of Table 4 shows that this type of pattern has the highest rank 1 and is the most significant factor, followed by the orientation of the pattern with rank 2 and density of the pattern with rank 3 . The mould thickness, V/A ratio and grade of material have been ranked at 4,5 and 6 , respectively. The effect of different input factors on mean $S / N$ ratio has been shown in Fig. 5. The higher value of the $\mathrm{S} / \mathrm{N}$ ratio represents less surface roughness. 
Table $3 S / N$ ratios for surface roughness

\begin{tabular}{|c|c|c|c|c|c|c|c|c|c|c|}
\hline \multirow[t]{2}{*}{ Exp. no. } & \multicolumn{6}{|l|}{ Input factor } & \multicolumn{3}{|c|}{ Surface roughness $\left(R_{a}\right)$ in $\mu \mathrm{m}$} & \multirow[t]{2}{*}{$S / N$ ratio $(\mathrm{dB})$} \\
\hline & $\mathrm{TP}$ & VA & OP & DP & MT & GM & $\mathrm{R} 1$ & $\mathrm{R} 2$ & $\mathrm{R} 3$ & \\
\hline 1 & Wax coated & 2.75 & 0 & Low density & 7 & SS $304 \mathrm{~L}$ & 1.912 & 1.592 & 1.828 & -5.021 \\
\hline 2 & Wax coated & 2.75 & 45 & High density & 8 & SS 316 & 2.902 & 2.505 & 2.719 & -8.671 \\
\hline 3 & Wax coated & 2.75 & 90 & Solid & 9 & SS 304 & 3.981 & 3.712 & 3.874 & -11.726 \\
\hline 4 & Wax coated & 3.34 & 0 & Low density & 8 & SS 316 & 1.601 & 1.345 & 1.545 & -3.528 \\
\hline 5 & Wax coated & 3.34 & 45 & High density & 9 & SS 304 & 2.996 & 2.645 & 2.515 & -8.711 \\
\hline 6 & Wax coated & 3.34 & 90 & Solid & 7 & SS $304 \mathrm{~L}$ & 3.114 & 2.917 & 2.896 & -9.476 \\
\hline 7 & Wax coated & 4.25 & 0 & High density & 7 & SS 304 & 1.726 & 1.645 & 1.517 & -4.252 \\
\hline 8 & Wax coated & 4.25 & 45 & Solid & 8 & SS $304 \mathrm{~L}$ & 2.202 & 2.203 & 2.378 & -7.092 \\
\hline 9 & Wax coated & 4.25 & 90 & Low density & 9 & SS 316 & 2.751 & 2.958 & 2.916 & -9.177 \\
\hline 10 & Uncoated & 2.75 & 0 & Solid & 9 & SS 316 & 3.987 & 4.250 & 3.884 & -12.135 \\
\hline 11 & Uncoated & 2.75 & 45 & Low density & 7 & SS 304 & 4.158 & 4.253 & 4.233 & -12.496 \\
\hline 12 & Uncoated & 2.75 & 90 & High density & 8 & SS $304 \mathrm{~L}$ & 4.888 & 4.748 & 4.891 & -13.702 \\
\hline 13 & Uncoated & 3.34 & 0 & High density & 9 & SS $304 \mathrm{~L}$ & 4.081 & 3.954 & 4.109 & -12.146 \\
\hline 14 & Uncoated & 3.34 & 45 & Solid & 7 & SS 316 & 4.222 & 4.874 & 4.951 & -13.430 \\
\hline 15 & Uncoated & 3.34 & 90 & Low density & 8 & SS 304 & 5.002 & 4.559 & 4.454 & -13.401 \\
\hline 16 & Uncoated & 4.25 & 0 & Solid & 8 & SS 304 & 3.800 & 4.623 & 4.278 & -12.562 \\
\hline 17 & Uncoated & 4.25 & 45 & Low density & 9 & SS $304 \mathrm{~L}$ & 4.537 & 4.529 & 4.595 & -13.167 \\
\hline 18 & Uncoated & 4.25 & 90 & High density & 7 & SS 316 & 4.558 & 4.309 & 4.856 & -13.217 \\
\hline & Average & & & & & & & & & -10.217 \\
\hline
\end{tabular}

Table 4 Response table for the mean $S / N$ ratios of surface roughness

\begin{tabular}{lllllll}
\hline Level & Input factor & \multicolumn{1}{l}{} \\
\cline { 2 - 6 } & TP & VA & OP & DP & MT & GM \\
\hline 1. & $-7.517^{\mathrm{a}}$ & -10.625 & $-8.274^{\mathrm{a}}$ & $-9.465^{\mathrm{a}}$ & $-9.649^{\mathrm{a}}$ & -10.101 \\
2. & -12.917 & -10.115 & -10.595 & -10.117 & -9.826 & $-10.026^{\mathrm{a}}$ \\
3. & - & $-9.911^{\mathrm{a}}$ & -11.783 & -11.070 & -11.177 & -10.525 \\
Delta & 5.400 & 0.714 & 3.509 & 1.605 & 1.528 & 0.498 \\
Rank & 1 & 5 & 2 & 3 & 4 & 6 \\
\hline
\end{tabular}

${ }^{\text {a }}$ Higher $S / N$ ratio
Figure 5 represents that the $\mathrm{S} / \mathrm{N}$ ratio of the surface roughness decreases when an uncoated plastic pattern is used instead of a wax-coated plastic pattern. It represents that with a coated plastic pattern, the surface roughness is less. This is due to the fact that the thin coating of wax fills the gaps between the different layers of the plastic pattern and a staircase effect produced by the FDM machine. The thin wax coating also increases the dimensions of the pattern, but this change in dimension is compensated by the solidification shrinkage of the metal. It has been observed that the castings obtained with wax-coated plastic patterns were not dimensionally inaccurate [25]. However, to be more precise, some pattern allowances may be used to balance the small increase in size due to wax coating. In this way, it can be deduced that wax-coated plastic patterns are better than uncoated plastic patterns in terms of surface roughness and chances of shell cracking.

There is very little effect of V/A ratio of the casting on the surface roughness of the casting. The $S / N$ ratio decreases with increase in orientation angle of the pattern. It means that the surface roughness increases with increase in the orientation angle. The orientation at $0^{\circ}$ angle produces the minimum surface roughness and the value of surface roughness increases as the orientation changes from $0^{\circ}$ to $90^{\circ}$.

The $S / N$ ratio related to density of the pattern represents that patterns with lesser density produce less surface roughness as compared to solid patterns. The probable 
Fig. 5 Main effect plots for mean $S / N$ ratios
Main Effects Plot for SN ratios

Data Means

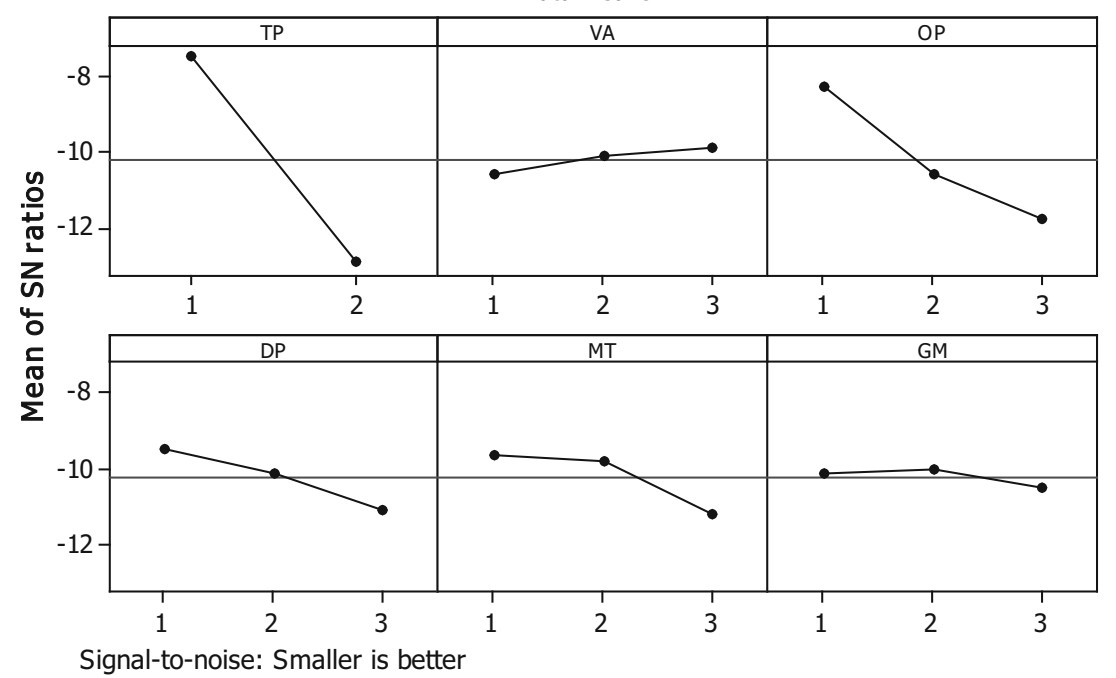

reason may be that more quantity of ash is produced by solid patterns as they are comparatively denser than the other two types. During burning of the pattern, some portion of this ash may stick to the cavity, which leads to a rough surface. The mould thickness affects the cooling rate of the casting. If the cooling rate is high, fine grains are produced. These fine grains are responsible for low surface roughness. When the mould thickness is increased, the cooling rate decreases and coarse grains are produced. These coarse grains give a rough surface. The effect of type of grade material is negligible on the surface roughness in the present case.

\subsection{Analysis of variance}

The results obtained from the experiments were analysed using ANOVA, which helps in predicting the significance of input factors taken for any desired response function. The knowledge of the contribution of individual factors is very important for the control of the final response. For this purpose, the sum of squares, degree of freedom, variance, $F$ ratio and percentage contribution of each factor are calculated. The sum of squares is a measure of the deviations of the experimental data from the mean value of data. The percentage contribution of a factor defines its significance rate on the surface roughness. Normally, the higher the percentage contribution, the more will be the effect of the input parameter on the output response. By controlling the factors with high contribution, the total variation can be reduced leading to improvement of the process performance.

ANOVA was carried out for the obtained $S / N$ ratios and the results are shown in Table 5. The percentage contribution of various input parameters was also calculated and shown.

Table 5 shows the calculated $F$ values for all the factors. Larger $F$ value indicates that the variation of the process parameter makes a big change in the performance characteristics. It shows that the factor TP and OP are significant at the $5 \%$ level of significance $(P<0.05)$. It can be observed from Table 5 that the percentage contribution of factor TP is $67.63 \%$, whereas the percentage contribution of factor OP is $19.70 \%$. The error variation due to uncontrollable parameters is approximately $3 \%$. The percentage contribution represents that the influence of wax coating on the FDM pattern is significantly higher than the other parameters, followed by orientation of the pattern. The effect of other parameters is statistically insignificant for surface roughness.

\subsection{Optimum set of parameters}

The higher the signal to noise ratio, the more favourable is the effect of the input variable on the output. From Table 4, the optimum levels (factor levels with the highest $S / N$ ratio) have been identified for the significant factors to achieve a minimum surface roughness. These optimum levels and their corresponding values are shown in Table 6.

Perusal of Table 6 shows that for the best surface roughness, the type of pattern should be wax coated and made with a $0^{\circ}$ angle of orientation in the FDM machine. The effect of other factors such as V/A ratio, density of pattern, mould thickness and the grade of the material is statistically insignificant and their levels can be selected on the basis of economic criteria. 
Table 5 Results of ANOVA for the $S / N$ ratios of surface roughness

\begin{tabular}{lcrrrll}
\hline Source & DOF & Sum of squares & Variance & \multicolumn{1}{l}{$F$} & \multicolumn{1}{l}{$P$} & Percentage contribution \\
\hline TP & 1 & 131.23 & 131.23 & 133.35 & $0.000 *$ & 67.63 \\
VA & 2 & 1.62 & 0.81 & 0.82 & 0.483 & 0.83 \\
OP & 2 & 38.22 & 19.11 & 19.42 & $0.002 *$ & 19.70 \\
DP & 2 & 7.82 & 3.91 & 3.97 & 0.080 & 4.03 \\
MT & 2 & 8.38 & 4.19 & 4.26 & 0.071 & 4.32 \\
GM & 2 & 0.86 & 0.43 & 0.44 & 0.663 & 0.44 \\
Residual error & 6 & 5.90 & 0.98 & & & 3.04 \\
Total & 17 & 194.05 & & & & 100 \\
\hline
\end{tabular}

* Significant factors at $95 \%$ confidence level
Table 6 Optimum set of factors for minimum surface roughness

\begin{tabular}{llll}
\hline Factor & Highest mean $S / N$ ratio & Optimum level & Optimum value \\
\hline TP & -7.517 & 1 & Wax coated \\
OP & -8.274 & 1 & $0^{\circ}$ \\
\hline
\end{tabular}

\subsection{Confirmatory experiments}

The experimental confirmatory test is the final step in verifying the results drawn based on Taguchi's design approach. The confirmatory experiment is highly recommended to verify the experimental results. The purpose of the confirmation experiment is to validate the conclusions drawn during the analysis phase. The confirmation experiment is performed by conducting a test with a specific combination of the factors and levels previously evaluated. In this study, two confirmatory experiments were conducted using the optimal levels of the significant process parameters. In this study, there are six input parameters and only two are significant. From Table 5, it can be seen that factors TP and OP are significant. The predicted optimum response in terms of $S / N$ ratio $\left(\eta_{\text {opt }}\right)$ is given by Eq. (3) [23, 26]. In this equation, $\bar{\eta}$ is the average of the $S / N$ ratio for all the observations (Table 3), whereas $\overline{\mathrm{TP}}_{1}$ and $\overline{\mathrm{OP}}_{1}$ are the highest mean $S / N$ ratio for factor TP and OP (Table 6).

$$
\begin{aligned}
& \text { Predicted } S / \text { Nratio }\left(\eta_{\text {pre }}\right)=\bar{\eta}+\left(\overline{\mathrm{TP}}_{1}-\bar{\eta}\right)+\left(\overline{\mathrm{OP}}_{1}-\bar{\eta}\right) \\
& \begin{aligned}
\eta_{\text {pre }}= & \left(\overline{\mathrm{TP}}_{1}\right)+\left(\overline{\mathrm{OP}}_{1}\right)-(\bar{\eta}) \\
& =(-7.517)+(-8.274)-(-10.217) \\
& =-5.574 \mathrm{~dB} .
\end{aligned}
\end{aligned}
$$

Using Eq. (1), the predicted surface roughness is $=1.899 \mu \mathrm{m}$.

Confirmatory experiments were performed using the obtained set of optimum values of the parameters. The confirmation test values of the surface roughness are 1.912 and $1.890 \mu \mathrm{m}$, which are closer to the predicted value.

\section{Conclusions}

In this paper, biomedical implants have been prepared using the FDM-assisted investment casting process. The various parameters affecting the surface roughness of the castings have been identified and optimised. It has been found that before using the plastic patterns for the investment casting process, it should be coated with a thin layer of wax. The layer of wax significantly reduces the surface roughness of the castings. The layer of wax also reduces the chances of shell cracking during the pattern burnout stage. The density of the pattern should be low to minimise the chances of shell cracking. It has also been observed that during preparation of the ABS patterns on the FDM machine, the orientation of the part should be at $0^{\circ}$ angle. Further studies are required to find the effect of thickness of the wax coating and the required pattern allowances for maintaining the dimensional accuracy of the castings.

Acknowledgments The authors are thankful to UGC, New Delhi, for providing research grant under the Minor Research Project scheme. The authors are also thankful to the Manufacturing Research Lab (GNDEC, Ludhiana) and the Department of Mechanical Engineering (Punjabi University, Patiala) for providing research facilities. The authors are also thankful to Mr. Puran Singh (laboratory technician) and Er. Sunpreet Singh (SRF) for providing their technical support.

\section{References}

1. Chua CK, Leong KF, Lim CS (2010) Additive manufacturing principles and application, 3rd edn. World Scientific Publishing, Singapore

2. Cheah CM, Chua CK, Lee CW, Feng C, Totong K (2005) Rapid prototyping and tooling techniques: a review of applications for rapid investment casting. Int $\mathrm{J}$ Adv Manuf Technol 25(3-4):308-320

3. Kumar P, Ahuja IPS, Singh R (2012) Application of fusion deposition modelling for rapid investment casting-a review. Int J Mater Eng Innov 3(3-4):204-227 
4. Kumar P, Singh R, Ahuja IPS (2013) A framework for developing a hybrid investment casting process. Asian Rev Mech Eng 2(2):49-55

5. Rosochwski A, Matuszak A (2000) Rapid tooling: the state of the art. J Mater Process Technol 106(1-3):191-198

6. Sushila B, Karthik K, Radhakrishnan P (1999) Rapid tooling for casting- a case study on application of rapid prototyping processes. Indian Foundry J 45(11):213-216

7. Lee CW, Chua CK, Cheah CM, Tan LH, Feng C (2004) Rapid investment casting: direct and indirect approaches via fused deposition modelling. Int J Adv Manuf Technol 23(1-2):93-101

8. Chua CK, Feng C, Lee CW, Ang GQ (2005) Rapid investment casting: direct and indirect approaches via model maker II. Int $\mathrm{J}$ Adv Manuf Technol 25(1-2):26-32

9. Nyembwe K, Beer DJD, Van Der Walt JG, Bhero S (2012) Assessment of surface finish and dimensional accuracy of tools manufactured by metal casting in rapid prototyping sand moulds. S Afr J Ind Eng 23(3):130-143

10. Kumar P, Singh R, Ahuja IPS (2005) Investigations for mechanical properties of hybrid investment casting: a case study. Mater Sci Forum 808:89-95

11. Anitha R, Arunachalam S, Radhakrishnan P (2001) Critical parameters influencing the quality of prototypes in fused deposition modeling. J Mater Process Technol 118(1-3):385-388

12. Ahn D, Kweon JH, Kwon S, Song J, Lee S (2009) Representation of surface roughness in fused deposition modeling. J Mater Process Technol 209(15-16):5593-5600

13. Garg A (2005) A fuzzy Taguchi approach for improving dimensional accuracy of fused deposition modelling (FDM) built parts, B.Tech. Thesis, Department of Mechanical Engineering, NIT, Rourkela, India

14. Vasudevarao B, Natarajan DP, Razdan A, Henderson M (2000) Sensitivity of RP surface finish to process parameter variation. In: Proceedings of 11th Solid Freeform Fabrication Symposium, University of Texas, Austin, pp 252-258
15. Thrimurthulu K, Pandey PM, Reddy NV (2004) Optimum part deposition orientation in fused deposition modeling. Int $\mathbf{J}$ Mach Tools Manuf 44(6):585-594

16. Bakar NSA, Alkahari MR, Boejang H (2010) Analysis on fused deposition modelling performance. J Zhejiang Univ Sci A 11(12):972-977

17. Chang DY, Huang BH (2010) Studies on profile error and extruding aperture for the rp parts using the fused deposition modeling process. Int J Adv Manuf Technol 53(9-12):1027-1037

18. Galantucci LM, Lavecchia F, Percoco G (2010) Experimental study aiming to enhance the surface finish of fused deposition modeled parts. CIRP Ann Manuf Technol 58(1):189-192

19. Kuo CS, Sheng J (2013) A simple method for improving surface quality of rapid prototype. Indian J Eng Mater Sci 20(6):465-470

20. Boschetto A, Bottini L (2015) Surface improvement of fused deposition modeling parts by barrel finishing. Rapid Prototyp J 21(6):686-696

21. Akhil KT, Arul S, Sellamuthu R (2014) The effect of section size on cooling rate, microstructure and mechanical properties of A356 aluminium alloy in casting. Proced Mater Sci 5:362-368

22. Askeland Donald R, Phule PP (2004) Essentials of materials science and engineering. Thomson, Ontario

23. Sood AK, Ohdar RK, Mahapatra SS (2009) Improving dimensional accuracy of fused deposition modelling processed part using grey taguchi method. Mater Des 30:4243-4252

24. MINITAB 16 Statistical software package, User Manual

25. Kumar P, Singh R, Ahuja IPS (2015) Investigations on dimensional accuracy of the components prepared by hybrid investment casting. J Manuf Process 20(3):525-533

26. Krishnaiah K, Shahabudeen P (2012) Applied design of experiments and taguchi methods. PHI Learning Pvt. Ltd., New Delhi, p 248 